\title{
Update on extended release quetiapine fumarate in schizophrenia and bipolar disorders
}

This article was published in the following Dove Press journal:

Neuropsychiatric Disease and Treatment

7 November 2012

Number of times this article has been viewed

\author{
Nizar El-Khalili \\ Alpine Clinic, Lafayette, IN, USA
}

Correspondence: Nizar El-Khalili

Alpine Clinic, 3660 Rome Dr,

Lafayette, IN 47905, USA

Tel +l 7654469394

Fax +I 7654478875

Email elkhalilmd@aol.com
Abstract: The atypical antipsychotic quetiapine fumarate is available both as an immediate release (IR) and as an extended release (XR) formulation allowing flexibility of dosing for individual patients. Approved uses of quetiapine XR include the treatment of schizophrenia (including maintenance therapy for prevention of relapse), the treatment of bipolar disorder (manic and depressive episodes), and the prevention of recurrence in patients with bipolar disorder who respond to quetiapine XR. This narrative review provides an update on quetiapine XR in these indications. The pharmacological profile of quetiapine, including a moderate affinity for dopamine $\mathrm{D}_{2}$ receptors and higher affinity for serotonin 5-hydroxytryptophan $(5-\mathrm{HT})_{2 \mathrm{~A}}$ receptors, may explain its broad efficacy and low propensity for extrapyramidal symptoms (EPS). The XR formulation has similar bioavailability but prolonged plasma levels compared with the IR formulation, allowing for less frequent (once-daily) dosing. Clinical studies have confirmed the efficacy of quetiapine XR in relieving the acute symptoms of schizophrenia during shortterm trials, and reducing the risk for relapse in long-term studies. Direct switching from the IR formulation to the same dose of the XR formulation did not reveal any loss of efficacy or tolerability issues, and switching patients to quetiapine XR from conventional or other atypical antipsychotics (for reasons of insufficient efficacy or tolerability) also proved to be beneficial and generally well tolerated. In bipolar disorder, quetiapine XR has also proven effective in relieving acute depressive and manic symptoms. Adverse events with quetiapine XR in patients with either schizophrenia or bipolar disorder are similar to those associated with the IR formulation, the most common being sedation, dry mouth, somnolence, dizziness, and headache. The low propensity for EPS is maintained with the XR formulation. Overall, evidence from clinical trials suggests that quetiapine XR is an effective and generally well-tolerated treatment option in patients with schizophrenia and bipolar disorder.

Keywords: quetiapine, extended release, schizophrenia, bipolar disorders

\section{Introduction}

Neuropsychiatric disorders provide the greatest contribution to total disease burden worldwide, greater than either cardiovascular disease or cancer. ${ }^{1}$ Both schizophrenia and bipolar disorder contribute substantially to this burden, with schizophrenia being the fifth leading cause of years lost to disability among men and the sixth leading cause among women, and bipolar disorder occupying the seventh and eighth positions, respectively. $^{2}$

Schizophrenia and bipolar disorder are both debilitating and isolating diseases that impose a significant burden on the lives of those affected. Effective management for these conditions remains a significant clinical challenge, particularly in the long term. 
To be successful, pharmacological treatment should be individualized and provide a balance between efficacy and tolerability. ${ }^{3}$ Atypical antipsychotics are considered first-line agents for schizophrenia, ${ }^{4,5}$ acute bipolar mania, and maintenance treatment of bipolar disorder. ${ }^{6,7}$ In addition, quetiapine ${ }^{7,8}$ and olanzapine ${ }^{9}$ (as part of the olanzapine fluoxetine combination) are both recommended for bipolar depression.

Immediate release quetiapine fumarate (quetiapine IR) is a well established atypical antipsychotic treatment for patients with schizophrenia, having shown efficacy across a broad range of symptoms (positive, negative, cognitive, and affective). ${ }^{10-13}$ Also, a large body of evidence supports quetiapine IR as monotherapy or adjunct to lithium or divalproex in the treatment of manic episodes in bipolar disorder. Large-scale trials have demonstrated efficacy in bipolar mania, ${ }^{14,15}$ depression, ${ }^{16-20}$ and bipolar maintenance. ${ }^{21-23}$ Quetiapine IR has also been demonstrated to improve anxiety symptoms, quality of life, and quality of sleep in patients with bipolar depression. ${ }^{24-26}$ Extended release quetiapine fumarate (quetiapine XR) is a once-daily formulation developed to provide patients and physicians with a more convenient dosing regimen and a simpler dose initiation. ${ }^{27}$ Studies of pharmacotherapies in general show that patients are more adherent to a once-daily dosing schedule, compared with more frequent dosing. ${ }^{28}$ Improved adherence to medications for the treatment of schizophrenia has been shown to lead to better treatment outcomes, including reduced need for rehospitalization and reduced incidence of suicide attempts. ${ }^{29,30}$

Quetiapine XR is approved for multiple indications, which vary by country; readers should consult their local prescribing information for complete details. Quetiapine XR is currently approved in the US ${ }^{27}$ and several other countries for the treatment of schizophrenia, acute manic and mixed episodes associated with bipolar disorder, and acute treatment of depressive episodes associated with bipolar disorder. Quetiapine XR is also approved for relapse prevention in patients with stable schizophrenia, maintenance treatment of bipolar disorder as adjunctive therapy to lithium or divalproex in the US, ${ }^{27}$ for recurrence prevention in bipolar disorder as monotherapy in the EU, ${ }^{31}$ and for add-on treatment of major depressive episodes in patients with major depressive disorder (MDD) who have had suboptimal response to antidepressant monotherapy in the US and EU. ${ }^{32,33}$ Table 1 provides an overview of the recommended dosing schedules for quetiapine IR and XR in schizophrenia and bipolar mania and depression and MDD. ${ }^{27}$ Quetiapine XR has a rapid titration schedule, which means an effective dose can be reached by day 2 in patients with schizophrenia and day 4 in patients with bipolar mania.

This narrative review will examine the pharmacokinetics, pharmacology, efficacy, and tolerability of quetiapine XR in patients with schizophrenia and bipolar disorder as reported in independent investigator and industry-sponsored papers and will discuss the potential clinical benefits of this formulation in the treatment of these diseases.

\section{Pharmacokinetic overview of quetiapine $X R$}

Quetiapine XR and IR each have a linear pharmacokinetic profile and an elimination half-life of approximately 7 hours when administered at doses within the recommended therapeutic

Table I Dose initiation schedule for extended-release quetiapine in schizophrenia, bipolar disorder, and major depressive disorder according to US prescribing information ${ }^{27}$

\begin{tabular}{|c|c|c|}
\hline Indication & Dosing instructions $^{a}$ & $\begin{array}{l}\text { Recommended } \\
\text { dose/dose range }\end{array}$ \\
\hline Schizophrenia & $\begin{array}{l}\text { Day I: } 300 \mathrm{mg} / \text { day } \\
\text { Dose increases can be made at intervals as short } \\
\text { as I day and in increments of up to } 300 \mathrm{mg} / \text { day }\end{array}$ & $400-800 \mathrm{mg} /$ day \\
\hline Schizophrenia maintenance (monotherapy) & $400-800 \mathrm{mg} / \mathrm{day}$ & $400-800 \mathrm{mg} /$ day \\
\hline $\begin{array}{l}\text { Bipolar mania (acute monotherapy or as an adjunct to } \\
\text { lithium or divalproex) }\end{array}$ & $\begin{array}{l}\text { Day I: } 300 \mathrm{mg} \\
\text { Day 2: } 600 \mathrm{mg} \\
\text { Day 3: between } 400 \mathrm{mg} \text { and } 800 \mathrm{mg}\end{array}$ & $400-800 \mathrm{mg} /$ day \\
\hline Depressive episodes associated with bipolar disorder & $\begin{array}{l}\text { Day I: } 50 \mathrm{mg} \\
\text { Day 2: } 100 \mathrm{mg} \\
\text { Day 3: } 200 \mathrm{mg} \\
\text { Day 4: } 300 \mathrm{mg}\end{array}$ & $300 \mathrm{mg} /$ day \\
\hline $\begin{array}{l}\text { Bipolar I disorder (maintenance treatment as an adjunct } \\
\text { to lithium or divalproex) }\end{array}$ & $400-800 \mathrm{mg} /$ day & $400-800 \mathrm{mg} /$ day \\
\hline Major depressive disorder (adjunctive therapy with antidepressants) & $\begin{array}{l}\text { Day I and 2: } 50 \mathrm{mg} \\
\text { Day } 3 \text { and } 4: 150 \mathrm{mg}\end{array}$ & $150-300 \mathrm{mg} /$ day \\
\hline
\end{tabular}

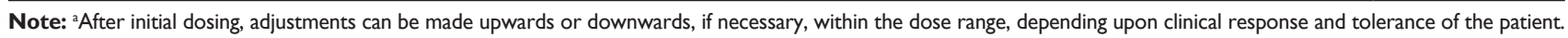


range. ${ }^{34,35}$ While the XR and IR formulations provide equivalent bioavailability, time to attainment of peak plasma concentration $\left(\mathrm{t}_{\max }\right)$ is prolonged ( 5 hours and 2 hours, respectively), and higher plasma levels are sustained for a longer period of time with the XR formulation. Consequently, less frequent (once-daily) dosing is required for quetiapine XR to maintain therapeutic drug concentrations. ${ }^{36}$

An open-label, randomized, crossover study in patients with schizophrenia, schizoaffective disorder, or bipolar disorder has demonstrated that evening dosing of quetiapine XR ensures lower plasma levels of quetiapine during the day. ${ }^{36}$ The study demonstrated equivalent areas under the 24-hour quetiapine plasma concentration curve with the XR and IR formulations. Once-daily dosing of quetiapine XR $300 \mathrm{mg}$ gave rise to a mean peak plasma concentration $\left(\mathrm{C}_{\max }\right)$ approximately $13 \%$ lower than that observed with twice-daily dosing of quetiapine IR $150 \mathrm{mg}$ (ratio of means XR/IR, 0.87; 90\% confidence interval [CI] 0.77-0.99); the authors described this as being relatively close; equivalence was predetermined as $90 \% \mathrm{CI}$ within the range $0.80-1.25 .{ }^{36}$

Although food has a minimal effect on quetiapine absorption in the IR formulation, ${ }^{34,38}$ consumption of a high-fat meal increases bioavailability of quetiapine in the XR formulation. ${ }^{27}$ Therefore, it is recommended that quetiapine XR be taken without food, although intake of a light meal (300 calories, no fat) has no significant effect on steady-state pharmacokinetics. ${ }^{37}$ If, as recommended, quetiapine XR is taken once-daily in the evening, the clinical impact of food consumption on bioavailability should be minimized.

\section{Mechanism of action of quetiapine}

The receptor-binding profiles of quetiapine and its major active human metabolite, norquetiapine (N-desalkylquetiapine), may provide an explanation for the broad clinical efficacy profile observed. ${ }^{39}$ Both quetiapine and norquetiapine have moderate affinity for dopamine (D) ${ }_{2}$ receptors and are potent antagonists of serotonin 5-hydroxytryptophan $(5-\mathrm{HT})_{2 \mathrm{~A}}$ receptors. ${ }^{40}$ In addition, quetiapine and norquetiapine bind to the 5- $\mathrm{HT}_{1 \mathrm{~A}}$ and $5-\mathrm{HT}_{1 \mathrm{C}}$ receptors with a moderateto-high affinity, which is similar to that of established antidepressants. ${ }^{41}$ Norquetiapine is also a potent inhibitor of the norepinephrine transporter (NET). Positron emission tomography (PET) imaging in nonhuman primates has demonstrated quetiapine and norquetiapine occupancy at $\mathrm{D}_{2}$, $5-\mathrm{HT}_{2 \mathrm{~A}}$, and norquetiapine occupancy at the NET at clinically relevant plasma levels. ${ }^{42}$ These combined pharmacological properties of quetiapine have not been described for any other psychotropic drug.
Evidence suggests that dopamine plays a key role in the neurobiology of psychotic symptoms in schizophrenia and bipolar mania. Occupancy of $\mathrm{D}_{2}$ receptors is the primary means by which antipsychotic agents mediate their effect; ${ }^{43-46}$ however, it is also considered to be the main mechanism responsible for inducing extrapyramidal symptoms (EPS), with a greater duration of $\mathrm{D}_{2}$ blockade associated with increased risk of EPS. Atypical antipsychotics, including quetiapine, are associated with a reduced incidence of EPS compared with conventional antipsychotics, a finding believed to be a result of their rapid dissociation from $\mathrm{D}_{2}$ receptors ${ }^{47}$ and higher affinity for $5-\mathrm{HT}_{2 \mathrm{~A}}$ receptors. ${ }^{48} \mathrm{PET}$ studies have shown low-to-moderate $\mathrm{D}_{2}$ occupancy by quetiapine throughout the therapeutic dose range for schizophrenia, 400-800 mg/day, due to its rapid dissociation from the receptor. ${ }^{49,50}$ Comparison of $\mathrm{D}_{2}$ receptor binding at peak and trough plasma concentration in patients with schizophrenia found that quetiapine IR (twice daily) and quetiapine XR (once daily) 300, 600, and $800 \mathrm{mg} /$ day demonstrated comparable central $\mathrm{D}_{2}$ receptor occupancy. ${ }^{51}$ PET scans in healthy volunteers showed that $\mathrm{D}_{2}$ occupancy at maximum quetiapine plasma concentration was $32 \%$ in individuals treated with quetiapine XR $300 \mathrm{mg}$ once daily compared with $49 \%$ among those receiving quetiapine IR $300 \mathrm{mg}$ once daily. ${ }^{50}$ Only descriptive statistics were presented from these PET studies, and consequently these results should be interpreted in light of the small number of study subjects.

The etiology of depressive symptoms in bipolar disorder and MDD appears to be complex, and several neurotransmitters have been implicated as having a role. Consequently, the precise mechanism by which quetiapine exerts its antidepressant effect is not fully understood. However, the antidepressant effect of quetiapine would appear to be mediated, at least in part, by the NET inhibition and partial $5-\mathrm{HT}_{1 \mathrm{~A}}$ agonism of its metabolite, norquetiapine. ${ }^{41}$ Immobility times in the murine tail suspension test, a model for antidepressant effect, were prolonged in a dose-dependent manner following acute dosing with norquetiapine and were also decreased compared with administration of vehicle only during 14 days of dosing.

\section{Clinical efficacy studies}

A number of clinical trials have been conducted to evaluate the efficacy and safety of quetiapine XR in patients with schizophrenia and bipolar disorder over both the short and long term. In addition, the feasibility of switching from quetiapine IR or other antipsychotic medication to quetiapine XR has been investigated. ${ }^{52-58}$ 


\section{Schizophrenia - efficacy}

In schizophrenia, the quetiapine XR clinical trial program investigated efficacy in three acute placebo-controlled studies, an acute noninferiority study, and a long-term relapse prevention study.

\section{Acute studies}

Three 6-week trials were conducted to investigate the efficacy and safety of quetiapine XR and quetiapine IR versus placebo for the treatment of acute schizophrenia. ${ }^{55,57,59}$

Study D1444C00132 $2^{59}$ was a 6-week randomized, doubleblind, placebo-controlled study that enrolled 588 patients in 39 centers in Europe, Asia, and South Africa, with a Diagnostic and Statistical Manual of Mental Disorders, Fourth Edition (DSM-IV) diagnosis of acute schizophrenia. Patients were randomly assigned to receive quetiapine XR $400 \mathrm{mg} /$ day $(\mathrm{n}=113), 600 \mathrm{mg} /$ day $(\mathrm{n}=113), 800 \mathrm{mg} /$ day $(\mathrm{n}=121)$, quetiapine IR $400 \mathrm{mg} /$ day $(\mathrm{n}=123)$, or placebo $(n=118)$. Compared with placebo, the change from baseline in Positive and Negative Syndrome Scale (PANSS) total score at week 6 (primary efficacy endpoint) was statistically significant for all four active treatments (modified intent-totreat [MITT] population) (Figure 1). Patients randomized to placebo achieved a decrease in PANSS total score of 18.8 points compared with decreases of 24.8 ( $P=0.03$ versus placebo), $30.9(P<0.001)$, and $31.3(P<0.001)$ for the quetiapine XR 400,600, and $800 \mathrm{mg}$ /day groups, respectively, and $26.6(P=0.004)$ for quetiapine IR. Analysis of several secondary efficacy variables similarly showed a significant improvement with quetiapine XR and quetiapine IR compared with placebo. The PANSS response rate at week 6 was statistically significantly higher for all four active treatment groups compared with placebo (30.4\% placebo; $44.1 \%$ $[P<0.05], 60.4 \%[P<0.001]$, and $56.4 \%[P<0.001]$ for quetiapine XR 400,600, and $800 \mathrm{mg} /$ day, respectively, and $52.9 \%[P<0.001]$ for quetiapine IR). A similar pattern was reported for the Clinical Global Impressions (CGI)Improvement (CGI-I) response rate (all comparisons with placebo were statistically significant versus placebo) and the change in CGI-Severity of Illness (CGI-S) score (all comparisons except quetiapine XR $400 \mathrm{mg}$ /day were statistically significant versus placebo).

Study D1444C00133,,$^{57}$ a US-based 6-week, randomized, double-blind, placebo-controlled study that enrolled 565 patients with a DSM-IV diagnosis of schizophrenia, failed to demonstrate a statistically significant improvement in efficacy for quetiapine XR or IR compared with placebo. This outcome was in contrast to the results of study D1444C00132, and surprising given the proven efficacy of quetiapine IR in other studies in this patient group. The authors suggest that the lack of separation from placebo was likely due to an attenuated drug response, apparent around week 3 . This attenuation may, in turn, have been a result of the study's design, which allowed patients to remain as outpatients throughout. Thus, patients may have been less acutely ill than those who took part in study D1444C00132 and were less closely monitored. A post-hoc analysis of the data from this study was conducted to determine whether the outcomes were affected by the baseline severity of illness. In all, $45.2 \%$ of patients $(n=246)$ were markedly ill at baseline (CGI-S $\geq 5$ ), with the remainder of patients considered moderately ill (CGI-S $<5$ but $\geq 4$ ). Among markedly ill patients, those treated with quetiapine

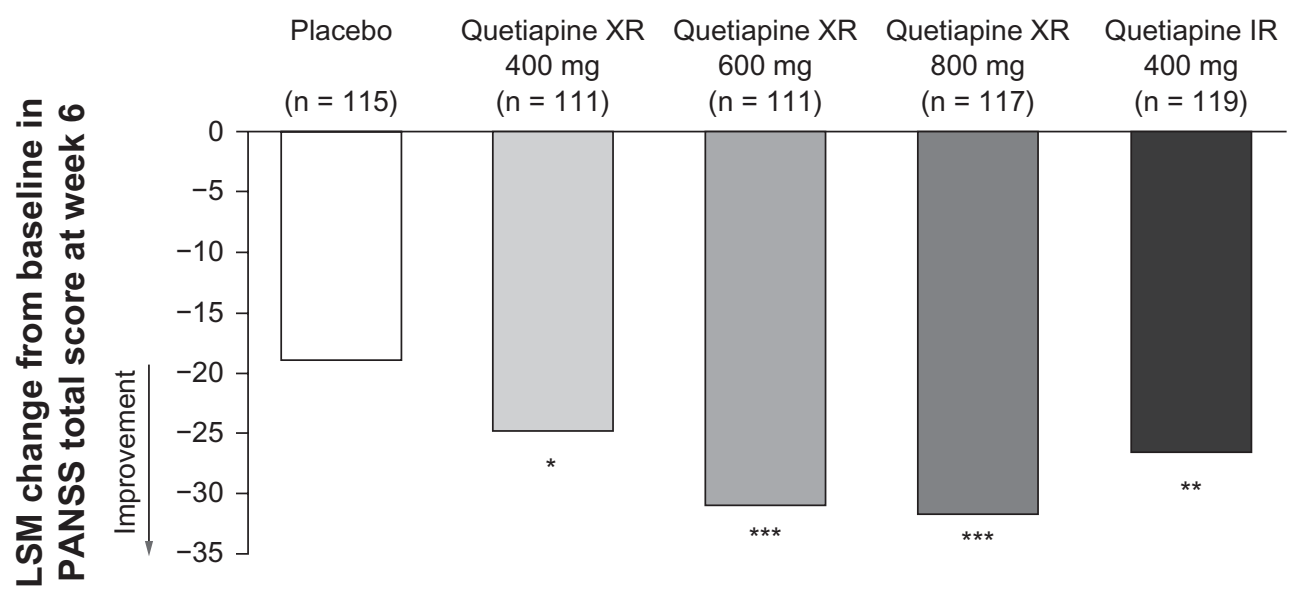

Figure I Change in PANSS total score from baseline to week 6 (modified intent-to-treat population). (c) Copyright 2007, Physicians Postgraduate Press. Reproduced with permission from Kahn RS, Schulz SC, Palazov VD, et al. Efficacy and tolerability of once-daily extended release quetiapine fumarate in acute schizophrenia: a randomized, double-blind, placebo-controlled study. J Clin Psychiatry. 2007;68(6):832-842. ${ }^{59}$

Note: $* P=0.05, * * P<0.01$, $* * * P<0.001$ versus placebo.

Abbreviations: IR, immediate release; LSM, least squares means; PANSS, Positive and Negative Syndrome Scale; XR, extended release. 
XR $600 \mathrm{mg}$ /day and quetiapine XR $800 \mathrm{mg}$ /day achieved a statistically significant improvement in the PANSS total score at week 6 compared with those who received placebo (MITT population; $P<0.05$ for both comparisons).

The identical design of studies D1444C00132 and D1444C00133 allowed another post-hoc analysis, this time of pooled data, to be performed. This analysis showed that, despite the failure of study D1444C00133 to achieve significance with regard to the primary endpoint (change in PANSS total score from baseline), in the pooled analysis quetiapine XR (400/600/800 mg/day) demonstrated significant improvement versus placebo at day $42 .{ }^{60}$ Change from baseline in PANSS total score first diverged significantly from placebo at day 14, day 21, and day 42 for quetiapine XR $800 \mathrm{mg} /$ day, $600 \mathrm{mg} /$ day, and $400 \mathrm{mg} /$ day, respectively. Analysis of change in PANSS total score at day 42 in the pooled dataset showed a statistically significant dose response for quetiapine XR (Jonckheere-Terpstra analysis). Effect sizes for changes in PANSS total scores were not reported in this post-hoc analysis.

The third study, 5077IL/0041, ${ }^{55}$ was a 6-week randomized, double-blind, placebo-controlled study that enrolled 532 patients in the US and Canada with a DSM-IV diagnosis of schizophrenia-catatonic, disorganized, paranoid, or undifferentiated schizophrenia. In this study, patients were randomly assigned to receive quetiapine $\mathrm{XR}$ at a dosage of 300,600 , or $800 \mathrm{mg} /$ day, quetiapine IR at a dosage of 300 or $600 \mathrm{mg} /$ day, or placebo. Only quetiapine XR $600 \mathrm{mg} /$ day demonstrated significant improvements in the primary outcome measure (change in PANSS score from baseline to week 6). There was no significant improvement in PANSS total score over the duration of the study with quetiapine IR (300 or $600 \mathrm{mg} /$ day; MITT population), in contrast with the documented efficacy of quetiapine IR in patients with schizophrenia. This was considered to be a failed study due to the lack of separation from placebo. Factors including a high attrition rate and short study duration were considered to be contributory to this outcome. ${ }^{55}$

A 12-week open-label, Europe-based study found that quetiapine XR (flexibly dosed at 400-800 mg/day) was noninferior to risperidone at significantly reducing symptoms of depression in patients with schizophrenia or schizoaffective disorder, as measured by least squares means (LSM) change in Calgary Depression Scale for Schizophrenia (CDSS). ${ }^{61}$ Patients were required to have a Hamilton Rating Scale for Depression (HAM-D) score $\geq 20$ at baseline and a HAM-D Item 1 (depressed mood) score $\geq 2$. The primary endpoint in this study was change from baseline on the CDSS in the perprotocol (PP) population. Patients treated with quetiapine XR achieved a greater improvement from baseline compared with risperidone, and an exploratory analysis revealed that quetiapine XR was superior to risperidone ( $4 \mathrm{mg} /$ day) in relieving the symptoms of depression as assessed by analysis of variance $(P=0.0029)$ in this population.

\section{Relapse prevention}

Relapse prevention is an important clinical goal in the management of schizophrenia given the chronic nature of the disorder. Study D1444C00004 ${ }^{52}$ was a Europe-based, randomized, placebo-controlled study that enrolled 327 patients with clinically stable schizophrenia (DSM-IV) of at least 2 years' duration. Clinical stability was defined as a CGI-S score $\leq 4$ and unchanged treatment (both compound and dose) with antipsychotic therapy for at least 4 weeks prior to entering the study. Eligible patients were switched to open-label quetiapine XR for 16 weeks (300 mg on day 1 , $600 \mathrm{mg}$ on day 2 , and flexible dosing at $400-800 \mathrm{mg} /$ day thereafter). Patients who remained clinically stable throughout the 4-month stabilization period were then randomized to continue with quetiapine XR or to placebo. The primary endpoint of the study was the time to first schizophrenia relapse in the intent-to-treat (ITT) population. This study was terminated early after an interim analysis showed that significantly more patients receiving placebo relapsed, compared with patients receiving quetiapine XR. At the time of the interim analysis, the risk of relapse in the ITT population was reduced by $84 \%$ (hazard ratio $0.16 ; P<0.0001$ ) for patients who received quetiapine XR compared with placebo, and the estimated length of time for which $90 \%$ of patients remained relapse-free was 2.9 months for quetiapine XR compared with 0.7 months for placebo. A post-hoc analysis showed that placebo was associated with a significantly shorter time to loss of remission compared with quetiapine XR (hazard ratio $0.39 ; 95 \%$ CI $0.19-0.81 ; P=0.009) .{ }^{62}$

\section{Bipolar disorder - efficacy}

The efficacy of quetiapine XR compared with placebo in bipolar depression and bipolar mania has been examined in two acute studies.

\section{Bipolar depression}

Study D144CC0000256 was an 8-week, double-blind, placebo-controlled, US-based randomized study that enrolled 280 acutely depressed adults with bipolar I or II disorder. In the study, a significant reduction in Montgomery Åsberg Depression Rating Scale (MADRS) total score was observed with a fixed dose of quetiapine XR $300 \mathrm{mg}$ /day compared 
with placebo (MITT population). This improvement was consistently observed from week 1 to week 8 . Significant improvements in MADRS total score with quetiapine XR compared with placebo were observed for patients with bipolar I and bipolar II depression and for patients with rapid and nonrapid cycling bipolar disorder (Figure 2). Quetiapine XR significantly improved several secondary efficacy variables compared with placebo, including a significantly greater MADRS response rate $(\geq 50 \%$ reduction in MADRS total score; $65.4 \%$ versus $43.1 \% ; P<0.001$ ) and remission rate (MADRS total score $\leq 12$ points; $54.1 \%$ versus $39.4 \% ; P<0.05)$. Patients treated with quetiapine XR also achieved a significantly greater improvement on the CGI-Bipolar-Severity (CGI-BP-S) scale compared with placebo $(-1.8$ versus -1.2 , respectively; $P<0.001)$, and significantly more patients had a CGI-Bipolar-Change (CGIBP-C) score of "much improved" or "very much improved" compared with those in the placebo group (63.2\% versus $39.4 \%$, respectively at week $8 ; P<0.001)$.

\section{Bipolar mania}

In a second US-based acute study on bipolar disorder (D144CC00004) ${ }^{58}$ quetiapine XR (400-800 mg/day once daily) resulted in a statistically significantly greater improvement in Young Mania Rating Scale (YMRS) total score at week 3 compared with placebo. Patients recruited to this study $(n=316)$ were required to have a DSM-IV diagnosis of bipolar I disorder with at least 1 manic or mixed episode in the preceding 5 years. Improvement was recorded as early as day $4(P<0.001)$, with a statistically significant separation from placebo maintained throughout the 3 weeks of the study (MITT population). Analysis of several secondary efficacy variables similarly showed a significant improvement with quetiapine XR compared with placebo for the majority of outcomes including a greater proportion of patients achieving symptomatic response $(\geq 50 \%$ reduction in YMRS total score; $55.0 \%$ versus $33.3 \% ; P=0.001)$ and remission (YMRS score $\leq 12$ points; $41.6 \%$ versus $27.7 \% ; P=0.006$ ). In addition, patients treated with quetiapine XR achieved a significantly greater improvement on the CGI-BP-S (change from baseline: -1.51 versus $-1.02 ; P<0.001)$ and the CGIBP-C (endpoint score: 2.58 versus $3.18 ; P<0.001$ ).

\section{Switching studies - efficacy}

With the introduction of any novel antipsychotic, it is important to evaluate the possibility of switching to the

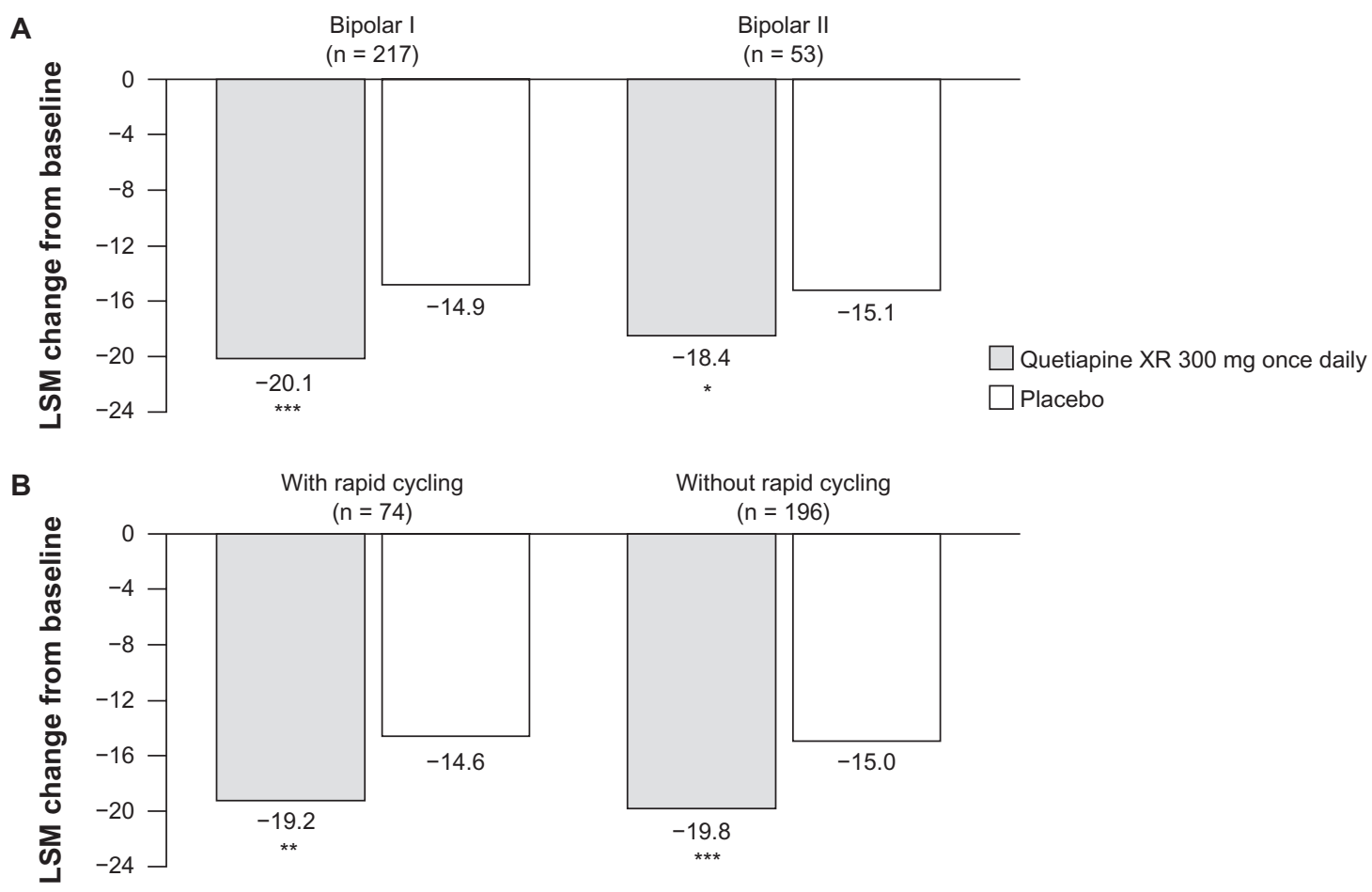

Figure 2 Mean change in MADRS total score in subgroups of patients with (A) bipolar I and bipolar II disorder and (B) with and without rapid cycling. C Copyright 20 I0. Elsevier. Reprinted with permission from Suppes T, Datto C, Minkwitz M, Nordenhem A, Walker C, Darko D. Effectiveness of the extended release formulation of quetiapine as monotherapy for the treatment of acute bipolar depression. J Affect Disord. 2010;12I(I-2): 106-1 I5. ${ }^{56}$

Note: $* P=0.05, * * P<0.01$, $* * * P<0.001$ versus placebo.

Abbreviations: LSM, least squares means; MADRS, Montgomery Åsberg Depression Rating Scale; XR, extended release. 
drug from other antipsychotic formulations to establish whether efficacy is maintained and to confirm that there are no safety concerns. Study D1444C00146 ${ }^{54}$ investigated the viability of switching from quetiapine IR to XR in outpatients with schizophrenia in Europe, Australia, Asia, Canada, South Africa, and the USA. A total of 562 adult patients with a DSM-IV diagnosis of schizophrenia entered a 4-week run-in period involving treatment with quetiapine IR (400-800 mg/day twice daily). Those considered clinically stable at the end of this run-in period $(n=497)$ were then randomized $(2: 1)$ to a once-daily equivalent dose of quetiapine XR $(n=331)$ or to continue with quetiapine IR $(n=166)$ for a further 6 weeks. Analysis of the proportion of patients who discontinued due to lack of efficacy, or whose PANSS total score increased by $\geq 20 \%$ from randomization, demonstrated noninferiority of quetiapine XR compared with quetiapine IR for the PP population $(5.3 \%$ versus $6.2 \%$, respectively; estimated treated difference $-0.83 \%$; $95 \% \mathrm{CI}-6.75-3.71 ; P=0.0017)$. The results of secondary efficacy variables (including mean change from randomization to day 42 on the PANSS scale [total and subscales], mean change in CGI-S, and the proportion of patients with a CGI-I score $\leq 4$ [no change or improvement]) were similar for quetiapine IR and XR, demonstrating that efficacy was maintained following the switch.

Study D1444C00147 53 investigated the potential clinical benefit of switching to quetiapine XR from conventional or atypical antipsychotic therapy in patients with schizophrenia who were experiencing suboptimal efficacy or tolerability with their existing treatment. In this 12-week open-label study conducted in Europe, Australia, Asia, Canada, South Africa, and the USA, 477 patients with a DSM-IV diagnosis of schizophrenia were switched from a previous antipsychotic medication using a cross-titration protocol. The reasons for initiating a therapy switch were insufficient efficacy $(n=315$ [66\%]) and insufficient tolerability $(\mathrm{n}=162$ [34\%]). Patients received quetiapine $\mathrm{XR} 300 \mathrm{mg}$ on day $1,600 \mathrm{mg}$ on day 2 , and then flexible doses of 400, 600, or $800 \mathrm{mg} /$ day from day 3 onwards. Previous antipsychotic medication was reduced by $25 \%$ on day $1,50 \%$ on day $2,75 \%$ on day 3 , and stopped on day 4 . A significant percentage $(62.8 \%$; $95 \%$ CI $58.4 \%-67.1 \% ; P<0.0001)$ of patients experienced a clinical benefit (defined as an improvement [decrease] in the CGI-CB score at week 12) after switching to quetiapine XR (MITT population). Patients also experienced improvements from baseline on the PANSS scale (LSM change: $-12.3 ; 95 \%$ CI -14.95 to $-9.58 ; P<0.001)$ and on the CGI-CB (LSM change: $-1.9 ; 95 \% \mathrm{CI}-2.32$ to $-1.38 ; P<0.001)$, the CGI-S (mean change: -0.7 [standard deviation 1.1]) and the CGI-I (LSM score: 2.88 ; 95\% CI 2.67-3.08; $P<0.001$ ).

No formal studies of switching from IR to XR or from a different atypical antipsychotic have been performed in bipolar disorder to date.

\section{Safety and tolerability Overview of tolerability - schizophrenia}

An overview of the profile and frequency of adverse events (AEs) in a pooled analysis of the three acute studies of quetiapine XR in schizophrenia (D1444C00132, D1444C00133, and 5077IL/0041) is provided in Table $2 .{ }^{63}$ Although only descriptive statistics were presented, the incidences of AEs appeared to be similar in all three treatment groups: quetiapine XR (69.5\%), quetiapine IR (72.5\%), and placebo (61.4\%). The profile of common AEs from this pooled analysis was comparable in the quetiapine XR, quetiapine IR, and placebo groups, and the majority of AEs were mildto-moderate in intensity. The most common AEs occurring with quetiapine $\mathrm{XR}$ in these acute studies were sedation, dry mouth, somnolence, dizziness, and headache. Serious AEs were reported in $4.4 \%, 3.9 \%$, and $4.4 \%$ of patients in the quetiapine $\mathrm{XR}$, quetiapine IR, and placebo groups, respectively, with AEs leading to withdrawal from treatment in $6.4 \%, 7.7 \%$, and $7.5 \%$ of patients, respectively.

In the long-term study (D1444C00004) of quetiapine XR in clinically stable patients with schizophrenia who were first switched from conventional and atypical antipsychotic treatment, a comparable percentage of patients reported AEs in the quetiapine XR $(31.9 \%)$ and placebo (40.8\%) groups in the randomized, double-blind phase. ${ }^{52}$ The majority of these AEs were mild-to-moderate in intensity. Two patients (1.9\%) who received placebo reported a serious AE; no serious AEs were reported among those treated with quetiapine XR. One patient in each group withdrew from treatment due to an AE.

\section{Overview of tolerability - bipolar disorder}

Only descriptive statistics were published in the acute study of quetiapine XR in bipolar mania. AEs were reported by $84.8 \%$ of patients treated with quetiapine XR 400-800 mg/day and by $66.9 \%$ of patients given placebo. ${ }^{58}$ The most common AEs occurring with quetiapine XR were sedation, dry mouth, somnolence, and headache. The tolerability profile was consistent with the known tolerability profile of quetiapine IR in bipolar mania (Table 3).

In the acute study of quetiapine XR in bipolar depression, again only descriptive statistics were presented; AEs were reported by $88.3 \%$ and $68.6 \%$ of patients in the quetiapine XR 


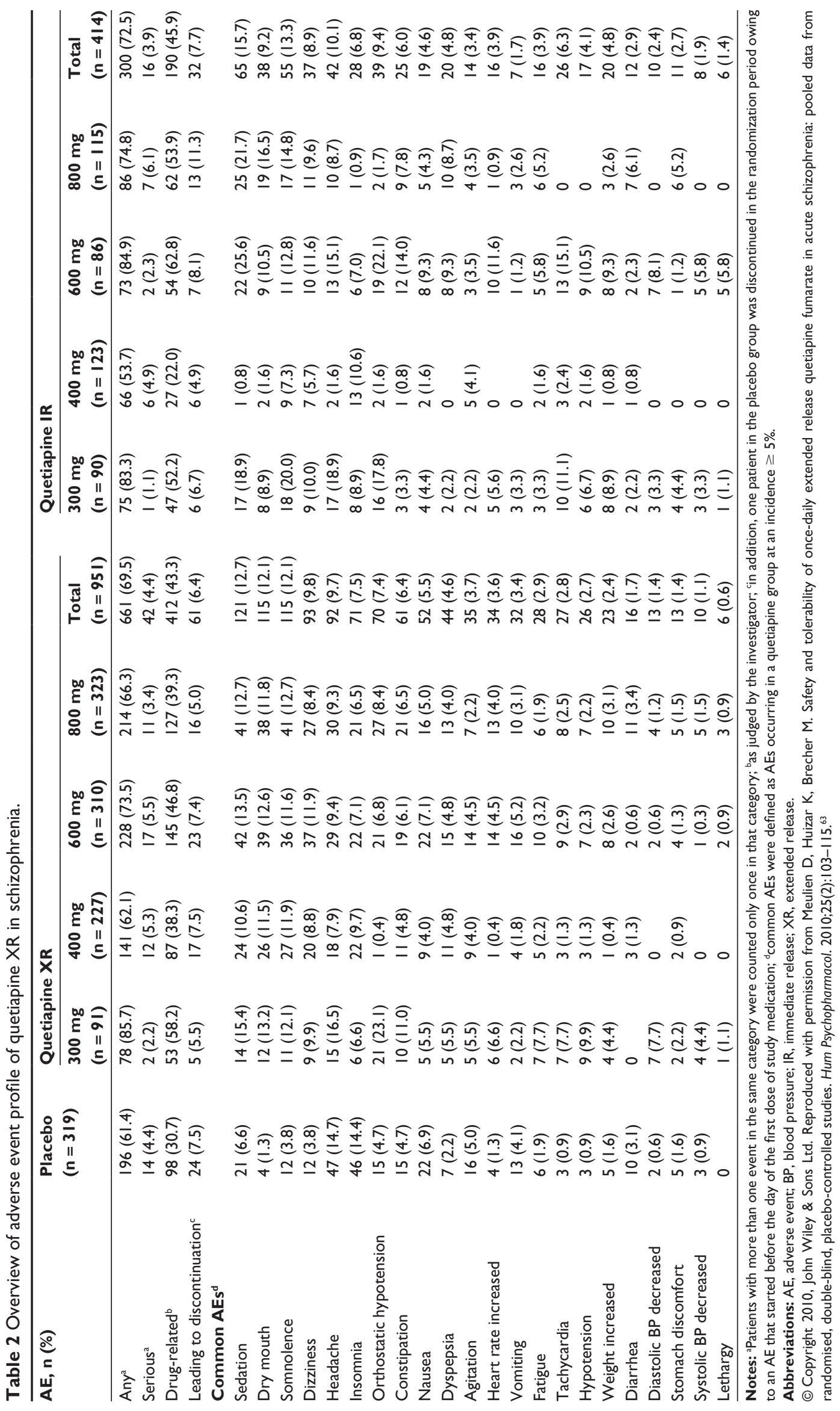


Table 3 Adverse event profile in bipolar mania and bipolar depression occurring in any quetiapine group at an incidence $\geq 5 \%{ }^{56,58}$

\begin{tabular}{|c|c|c|c|c|}
\hline \multirow[t]{2}{*}{ Adverse event, n (\%) } & \multicolumn{2}{|l|}{ Bipolar mania } & \multicolumn{2}{|c|}{ Bipolar depression } \\
\hline & $\begin{array}{l}\text { XR 400-800 mg } \\
(n=I 5 I)\end{array}$ & $\begin{array}{l}\text { Placebo } \\
(n=160)\end{array}$ & $\begin{array}{l}\text { XR } 300 \mathrm{mg} \\
(\mathrm{n}=137)\end{array}$ & $\begin{array}{l}\text { Placebo } \\
(n=140)\end{array}$ \\
\hline Any adverse event ${ }^{\mathrm{a}}$ & $128(84.8)$ & $107(66.9)$ & $121(88.3)$ & $96(68.6)$ \\
\hline Serious adverse events ${ }^{\mathrm{a}}$ & $6(4.0)$ & $13(8.1)$ & $2(1.5)$ & $2(1.4)$ \\
\hline Any adverse event leading to discontinuation & $7(4.6)$ & $13(8.1)$ & $17(12.4)$ & $2(1.4)$ \\
\hline \multicolumn{5}{|l|}{ Common adverse events } \\
\hline Dry mouth & $51(33.8)$ & II (6.9) & $51(37.2)$ & $10(7.1)$ \\
\hline Somnolence & $25(16.6)$ & $7(4.4)$ & $40(29.2)$ & $8(5.7)$ \\
\hline Sedation & $52(34.4)$ & $12(7.5)$ & $32(23.4)$ & $10(7.1)$ \\
\hline Dizziness & $15(9.9)$ & $7(4.4)$ & $18(13.1)$ & $15(10.7)$ \\
\hline Increased appetite & $6(4.0)$ & $3(1.9)$ & $17(12.4)$ & $8(5.7)$ \\
\hline Headache & $18(11.9)$ & $22(13.8)$ & $13(9.5)$ & $14(10.0)$ \\
\hline Constipation & $15(9.9)$ & $5(3.1)$ & II (8.0) & $9(6.4)$ \\
\hline Nausea & $3(2.0)$ & $4(2.5)$ & $10(7.3)$ & $10(7.1)$ \\
\hline Weight increased & $10(6.6)$ & $\mathrm{I}(0.6)$ & $10(7.3)$ & $2(1.4)$ \\
\hline Dyspepsia & $10(6.6)$ & $6(3.8)$ & $9(6.6)$ & $\mathrm{I}(0.7)$ \\
\hline Fatigue & $10(6.6)$ & $6(3.8)$ & $8(5.8)$ & $3(2.1)$ \\
\hline
\end{tabular}

Note: aPatients with more than one event in the same category were counted only once in that category.

Abbreviation: $X R$, extended release.

(C) Copyright 2010, Elsevier. Reproduced with permission from Suppes T, Datto C, Minkwitz M et al. Effectiveness of the extended release formulation of quetiapine as monotherapy for the treatment of acute bipolar depression. J Affect Disord. 2010;121(I-2):106-115. ${ }^{56}$

$300 \mathrm{mg} /$ day and placebo groups, respectively. ${ }^{56}$ The most common AEs occurring with quetiapine XR were dry mouth, somnolence, sedation, dizziness, and increased appetite. The tolerability profile was consistent with the known tolerability profile of quetiapine IR in bipolar depression (Table 3).

\section{Adverse events of special interest}

\section{Somnolence}

Somnolence was among the most frequently reported AEs across all three acute schizophrenia studies (Table 2). ${ }^{63}$ The majority of somnolence-related AEs ( $>96 \%$ in the quetiapine-treatment groups) were mild-to-moderate in intensity with a median onset of 4 days with placebo, 3 days with quetiapine XR, and 2 days with quetiapine IR. The duration of somnolence was generally $<3$ weeks (mean duration: 9.8, 18.1, and 17.2 days in the placebo, quetiapine XR, and quetiapine IR groups, respectively). Consistent with this finding, in the relapse prevention study, the incidence of somnolence with quetiapine $\mathrm{XR}$ was reduced during the long-term treatment phase $(0.0 \%)$ compared with the initial 16 -week stabilization period (19.3\%). ${ }^{52}$ Similarly, in the acute bipolar depression and mania studies, somnolence was among the most commonly reported AEs, and typically emerged during the first days of treatment. ${ }^{56,58}$

\section{Sexual side effects}

Pooled data from three Phase III clinical trials of quetiapine $\mathrm{XR}$ versus quetiapine IR in acute schizophrenia that enrolled almost 1700 patients indicated that sexual side effects were uncommon. These studies reported that in the quetiapine XR group, erectile dysfunction was experienced by two patients and delayed ejaculation was experienced by one patient. In the quetiapine IR-treated group, one patient reported decreased libido and one patient reported sexual dysfunction. ${ }^{63}$

\section{QT interval prolongation}

There was no evidence of an increased mean QT interval corrected for heart rate (QTc) with either quetiapine XR or IR in a pooled analysis of three large Phase III trials of patients with schizophrenia. In this analysis, the proportion of patients with a shift to a QTc $\geq 450 \mathrm{~ms}$ was $0.6 \%$ for both quetiapine formulations. ${ }^{63}$ Furthermore, no increase in QTc was reported in a long-term (1-year) study that assessed quetiapine XR in the prevention of psychotic relapse in patients with schizophrenia. ${ }^{52}$

\section{Extrapyramidal symptoms and tardive dyskinesia}

Fewer than $10 \%$ of patients with schizophrenia treated with quetiapine XR or quetiapine IR experienced AEs potentially related to EPS during acute treatment. ${ }^{63}$ The incidence of EPS among those treated with quetiapine XR was 7.5\%, with $7.7 \%$ of those treated with quetiapine IR and $4.7 \%$ of those who received placebo reporting an AE potentially related to EPS. No individual AE potentially related to EPS occurred at a rate $>3 \%$ in any treatment group. Most potentially EPS-related AEs were mild-to-moderate in intensity, and 
no relationship between quetiapine dose and $\mathrm{AE}$ severity was evident. The incidence of EPS during long-term quetiapine XR treatment was low and appeared comparable with placebo. ${ }^{52}$ The frequency of tardive dyskinesia (TD) was $0.2 \%, 0.5 \%$, and $0.3 \%$ in patients with acute schizophrenia treated with quetiapine XR, quetiapine IR, and placebo. ${ }^{63}$

In the acute bipolar depression study, the frequency of AEs related to EPS was $4.4 \%$ for those treated with quetiapine XR compared with $0.7 \%$ in the placebo group. ${ }^{56}$ The majority of patients experienced no change or improvements on the Simpson Angus Scale (SAS) and the Barnes Akathisia Rating Scale (BARS). Similarly, in the acute bipolar mania study, the majority of patients experienced no change or improved scores on the SAS and BARS scales. ${ }^{58,64}$

\section{Bodyweight and metabolic parameters}

A pooled analysis of data, from the three acute schizophrenia studies that presented descriptive statistics only, ${ }^{63}$ reported that $13.7 \%, 19.5 \%$, and $6.7 \%$ of patients treated with quetiapine XR, quetiapine IR, or placebo, respectively experienced Food and Drug Administration-defined clinically significant bodyweight gain ( $\geq 7 \%$ increase in weight from baseline). In the same analysis, the mean change from baseline in weight was $1.63 \mathrm{~kg}, 2.19 \mathrm{~kg}$, and $0.26 \mathrm{~kg}$ with quetiapine $\mathrm{XR}$, quetiapine IR, and placebo, respectively. In the long-term schizophrenia relapse prevention study, five patients $(5.4 \%)$ in the quetiapine XR group and one patient $(1 \%)$ in the placebo group experienced clinically significant weight gain between randomization and the end of treatment. ${ }^{52}$ The mean change in weight from enrolment to study end in patients receiving quetiapine XR throughout the relapse prevention study was $1.06 \mathrm{~kg}$. In terms of metabolic parameters, small differences from placebo were noted in terms of changes in plasma glucose and glycosylated hemoglobin $\left(\mathrm{HbA}_{1 \mathrm{c}}\right)$ levels, and no clinically relevant changes were noted for total cholesterol, high-density lipoprotein-cholesterol, or low-density lipoprotein-cholesterol among patients who completed the acute treatment studies. A modest mean increase in plasma triglyceride concentration was noted (quetiapine XR $0.17 \mathrm{mmol} / \mathrm{L}$; quetiapine IR $0.38 \mathrm{mmol} / \mathrm{L}$; placebo $0.11 \mathrm{mmol} / \mathrm{L}$ ); however, no dose relationship was evident and the proportion of patients who experienced a clinically relevant shift in fasting triglycerides was comparable between the quetiapine XR and quetiapine IR groups (17.9\% and 15.6\%, respectively). No clinically relevant changes in lipid levels were observed during long-term treatment with quetiapine XR. ${ }^{52}$

Clinically important weight gain ( $\geq 7 \%$ increase in bodyweight from baseline) was experienced by $8.2 \%$ and $0.8 \%$ of patients with bipolar depression treated with quetiapine XR and placebo, respectively. ${ }^{56}$ In a study of bipolar mania, 5.1\% versus $0 \%$ of patients receiving quetiapine XR versus placebo, respectively, experienced a clinically important weight gain. ${ }^{58}$ Mean changes in weight were $+1.3 \mathrm{~kg}$ and $-0.2 \mathrm{~kg}$ with quetiapine $\mathrm{XR}$ and placebo, respectively, in patients with bipolar depression and $+1.3 \mathrm{~kg}$ and $+0.1 \mathrm{~kg}$, respectively, in patients with bipolar mania. ${ }^{56,58}$ In the bipolar depression study, clinically important shifts were noted for fasting glucose $(5.8 \%$ versus $2.1 \%$ ), total cholesterol ( $7.1 \%$ versus $2.8 \%$ ), and triglycerides $(8.3 \%$ versus $7.5 \%)$ in patients receiving quetiapine XR and placebo, respectively. ${ }^{56}$ In the same study, mean changes in serum glucose, total cholesterol, high-density lipoproteincholesterol, and low-density lipoprotein-cholesterol were similar with quetiapine XR and placebo, although triglyceride levels increased with quetiapine XR and decreased with placebo (mean changes $+0.18 \mathrm{mmol} / \mathrm{L}$ and $-0.03 \mathrm{mmol} / \mathrm{L}$, respectively). A clinically important shift was noted for fasting glucose $(4.1 \%$ versus $1.6 \%$ ) only in the bipolar mania study. ${ }^{58}$

Currently, there is little information regarding quetiapine XR and the risk of developing diabetes mellitus. However, in the long-term study of prevention of psychotic relapse in patients with schizophrenia, quetiapine XR was not associated with treatment-emergent diabetes, and no AEs related to diabetes were reported. ${ }^{52}$

\section{Tolerability of $X R$ versus IR during dose initiation}

A post-hoc analysis of pooled data from two acute studies (D1444C00132 and D1444C00133) in schizophrenia was conducted to evaluate the tolerability of quetiapine XR during rapid dose initiation (in these studies target doses of quetiapine XR were reached by day 2 [400 and $600 \mathrm{mg} /$ day] and day $3[800 \mathrm{mg} /$ day $]) .{ }^{63}$ During the first week of treatment, the incidence of AEs was similar in the quetiapine XR and quetiapine IR groups. The most commonly reported AEs in this period were somnolence, sedation, dry mouth, and dizziness in the quetiapine XR and quetiapine IR groups. The incidence of serious AEs was low in both the quetiapine XR and quetiapine IR treatment groups.

Similarly, a US-based study (D1443C00040 AstraZeneca, data on file) investigated the tolerability of quetiapine IR and quetiapine XR during initial dosing and dose escalation in 139 patients with bipolar depression. Patients received placebo on day 1 and quetiapine XR or quetiapine IR on days 1-6 under the following schedule: $50 \mathrm{mg}$ on day 2 , $100 \mathrm{mg}$ on day $3,200 \mathrm{mg}$ on day 4, and $300 \mathrm{mg}$ on days 5 and 6 (mean dose $156.5 \mathrm{mg}$ for quetiapine XR and $157.6 \mathrm{mg}$ for quetiapine IR). The incidence of treatment-related AEs was 
$47.1 \%$ with quetiapine XR and $59.4 \%$ with quetiapine IR. The most commonly reported AEs for quetiapine XR were dry mouth, increased appetite, and somnolence. The most commonly reported AEs for quetiapine IR were increased appetite, dizziness, dry mouth, and headache. The incidence of AEs potentially related to EPS was $2.9 \%$ with quetiapine XR compared with $11.6 \%$ with quetiapine IR. Potentially clinically significant orthostatic changes were reported for $17.1 \%$ and $26.5 \%$ of patients receiving quetiapine XR and quetiapine IR, respectively.

Study D1443C00033, ${ }^{65}$ a randomized, double-blind, double-dummy, 2-period crossover study conducted in healthy subjects in the US, was designed to investigate the time course and intensity of sedation, measured using a visual analog scale, during dose initiation of quetiapine XR and quetiapine IR. After 1 hour on day 1 (primary endpoint) quetiapine XR was associated with a significantly reduced intensity of sedation compared with quetiapine IR. The level of sedation was lower with quetiapine XR compared with quetiapine IR for the first 7 hours post dosing, after which levels of sedation were comparable with both formulations.

\section{Tolerability when switching to quetiapine $X R$}

The safety data from the switching study in patients with schizophrenia indicated that the switch from quetiapine IR to quetiapine XR was not associated with any compromise in tolerability. ${ }^{54}$ The majority of AEs were mild-to-moderate in intensity, and the incidence of serious AEs $(\mathrm{n}=13)$ and serious AEs leading to discontinuation was low $(n=11)$ during the run-in period. The $\mathrm{AE}$ profile and effect on vital signs and laboratory data were generally consistent with other studies of quetiapine XR.

In the long-term relapse prevention study, in which switching from previous antipsychotic medication (conventional and atypical antipsychotics including olanzapine and risperidone) was achieved during a 4-day cross-titration period, the rate of withdrawal was low providing supporting evidence that patients can be switched from their previous medication with little difficulty. ${ }^{52}$ In the open-label stabilization phase of the study, four patients (1.2\%) discontinued due to AEs. No serious AEs were reported during the stabilization phase following switch, and the most common AEs (reported by $\geq 5 \%$ of patients) were somnolence (19.3\%) and dizziness (6.4\%). Severe AEs related to study treatment in the post-switch, stabilization phase comprised two reports of somnolence and one report each of constipation, dyspepsia, and epileptic seizure. ${ }^{52}$

In a further study of switching to quetiapine XR from a conventional or atypical antipsychotic $(n=477)$, eight patients
(1.7\%) discontinued due to AEs during the 4-day switching period. ${ }^{53}$ The most common AEs during the switching phase were sedation (12.4\%), somnolence (11.3\%), dizziness $(10.1 \%)$, and dry mouth $(9.0 \%)$. One patient experienced a serious AE while switching (breast abscess), but this was judged to be unrelated to treatment by the study investigator. ${ }^{53}$

\section{Discussion}

The management of schizophrenia and bipolar disorder continues to represent a considerable clinical challenge. In addition to the challenges of controlling acute symptoms, the chronic nature of both diseases means that treatment is not limited to an acute period but instead must extend over a long-term maintenance period, increasing the importance of having a wide variety of treatment options available.

The efficacy of quetiapine IR for the treatment of schizophrenia and bipolar disorder is well established. The data presented here and other clinical trial results in $\mathrm{MDD}^{66-71}$ show that quetiapine has a broad spectrum of activity, with both antipsychotic and antidepressant efficacy. Our increasing understanding of the mechanism of action of quetiapine, and its metabolite norquetiapine, helps to explain these seemingly distinct properties. Indeed, an increasing body of preclinical evidence indicates that moderate $\mathrm{D}_{2}$ affinity and low-potency $\mathrm{D}_{2}$ antagonism, combined with high-affinity NET inhibition and $5-\mathrm{HT}_{2 \mathrm{~A}}$ antagonism, may be key characteristics that contribute to the antipsychotic and antidepressant properties of quetiapine. ${ }^{39}$ Variations in the receptor binding profiles across the dose range may contribute toward the different dosing requirements for treatment of psychotic and depressive symptoms.

Quetiapine XR was developed to offer an alternative treatment option with once-daily dosing and a simplified dose titration schedule. Evidence from studies of patient adherence to treatment in several chronic conditions has shown that patients are more adherent with once-daily medications, compared with more frequently dosed formulations ${ }^{28}$ Thus, it can be hypothesized that the once-daily dosing schedule of quetiapine XR may help improve patient adherence to treatment and consequently may have a positive impact on patient outcomes; direct investigation in this regard is warranted. In addition, a pharmacoeconomic comparison study of quetiapine XR and IR would be useful to establish whether switching to quetiapine XR is cost-effective. Indeed, recent evidence suggests that the faster titration schedule of quetiapine XR may offer benefits in terms of the length of hospitalization for both schizophrenia and bipolar disorder, with inpatient use of quetiapine XR being associated with significant reductions in the length and cost of hospitalization. ${ }^{72}$ 
For patients with schizophrenia, switching to quetiapine XR from quetiapine IR is not associated with loss of efficacy and switching to quetiapine XR from a different antipsychotic, due to insufficient efficacy or tolerability, was associated with clinical benefit. ${ }^{53,54}$

The tolerability profile of quetiapine XR in schizophrenia and bipolar disorder is consistent with the profile for quetiapine IR. In acute studies in both schizophrenia and bipolar disorder, sedation, dry mouth, and somnolence were the most common AEs recorded. The association of quetiapine XR with somnolence is shared by many other atypical antipsychotics. ${ }^{73}$ In schizophrenia, the majority of instances of somnolence associated with either formulation of quetiapine appear to occur early in treatment and to be transient. ${ }^{52,63}$ Furthermore, in comparison with quetiapine IR, quetiapine $\mathrm{XR}$ is associated with milder cases of sedation and somnolence, particularly during dose initiation in healthy volunteers. ${ }^{65}$ The frequency of EPS appears to be low for both quetiapine IR and quetiapine XR and only rarely results in treatment discontinuation.

It is important to consider the patients' opinion of their medication; therefore, future trials evaluating the use of quetiapine XR in patients with schizophrenia and bipolar disorder should incorporate patient-reported outcomes to provide further evidence for the benefits of the formulation.

In conclusion, quetiapine XR represents an effective and generally well-tolerated treatment for schizophrenia and bipolar disorder that is initiated rapidly and taken only once daily.

\section{Acknowledgments}

The author thanks Dr Clemence Hindley, PhD, from Complete Medical Communications, who provided medical writing support funded by AstraZeneca.

\section{Disclosure}

Nizar El-Khalili has received research grants or has participated in advisory boards or speakers' bureaux for Alkermes, AstraZeneca, Eli Lilly, GlaxoSmithKline, Pfizer, sanofiaventis and Takeda.

Funding for the quetiapine XR studies discussed within this review was provided by AstraZeneca.

\section{References}

1. Prince M, Patel V, Saxena S, et al. No health without mental health. Lancet. 2007;370(9590):859-877.

2. World Health Organization. The global burden of disease 2004 update. 2008.

3. Weiden PJ, Preskorn SH, Fahnestock PA, Carpenter D, Ross R, Docherty JP. Translating the psychopharmacology of antipsychotics to individualized treatment for severe mental illness: a roadmap. J Clin Psychiatry. 2007;68(Suppl)7:1-48.
4. American Psychiatric Association. Practice guideline for the treatment of patients with schizophrenia [updated 2004]. Available from: http:// www.psychiatryonline.com/pracGuide/loadGuidelinePdf.aspx?file= Schizophrenia2ePG_05-15-06. Accessed January 21, 2010.

5. National Institute of Clinical Excellence. Core interventions in the treatment and management of schizophrenia in primary and secondary care (Clinical Guideline 1) [updated April 12, 2004]. Available from: http://www.nice.org.uk.

6. Grunze H, Vieta E, Goodwin GM, et al. The World Federation of Societies of Biological Psychiatry (WFSBP) guidelines for the biological treatment of bipolar disorders: update 2009 on the treatment of acute mania. World J Biol Psychiatry. 2009;10(2):85-116.

7. Yatham LN, Kennedy SH, Schaffer A, et al. Canadian Network for Mood and Anxiety Treatments (CANMAT) and International Society for Bipolar Disorders (ISBD) collaborative update of CANMAT guidelines for the management of patients with bipolar disorder: update 2009. Bipolar Disord. 2009;11(3):225-255.

8. Goodwin G. Evidence-based guidelines for treating bipolar disorder: revised second edition - recommendations from the British Association for Psychopharmacology. J Psychopharmacol. 2009;23:346-388.

9. Grunze H, Vieta E, Goodwin GM, et al. The World Federation of Societies of Biological Psychiatry (WFSBP) Guidelines for the Biological Treatment of Bipolar Disorders: update 2010 on the treatment of acute bipolar depression. World J Biol Psychiatry. 2010;11(2): 81-109.

10. Arango C, Bobes J. Managing acute exacerbations of schizophrenia: focus on quetiapine. Curr Med Res Opin. 2004;20(5):619-626.

11. Buckley PF. Efficacy of quetiapine for the treatment of schizophrenia: a combined analysis of three placebo-controlled trials. Curr Med Res Opin. 2004;20(9):1357-1363.

12. Hellewell JSE, Cameron-Hands D, Cantillon M. Seroquel ${ }^{\circledR}$ : evidence for efficacy in the treatment of hostility and aggression. Schizophr Res. 1998;29:154-155.

13. Leucht S, Kissling W, Davis JM. Second-generation antipsychotics for schizophrenia: can we resolve the conflict? Psychol Med. 2009;39(10):1591-1602.

14. Bowden CL, Grunze H, Mullen J, et al. A randomized, double-blind, placebo-controlled efficacy and safety study of quetiapine or lithium as monotherapy for mania in bipolar disorder. J Clin Psychiatry. 2005;66(1):111-121.

15. McIntyre RS, Brecher M, Paulsson B, Huizar K, Mullen J. Quetiapine or haloperidol as monotherapy for bipolar mania - a 12-week, double-blind, randomised, parallel-group, placebo-controlled trial. Eur Neuropsychopharmacol. 2005;15(5):573-585.

16. Calabrese JR, Keck PE Jr, Macfadden W, et al. A randomized, doubleblind, placebo-controlled trial of quetiapine in the treatment of bipolar I or II depression. Am J Psychiatry. 2005;162(7): 1351-1360.

17. McElroy SL, Weisler RH, Chang W, et al. A double-blind, placebocontrolled study of quetiapine and paroxetine as monotherapy in adults with bipolar depression (EMBOLDEN II). J Clin Psychiatry. 2010;71(2):163-174.

18. Thase ME, Macfadden W, Weisler RH, et al. Efficacy of quetiapine monotherapy in bipolar I and II depression: a double-blind, placebocontrolled study (the BOLDER II study). J Clin Psychopharmacol. 2006;26(6):600-609.

19. Vieta E, Calabrese JR, Goikolea JM, Raines S, Macfadden W. Quetiapine monotherapy in the treatment of patients with bipolar I or II depression and a rapid-cycling disease course: a randomized, doubleblind, placebo-controlled study. Bipolar Disord. 2007;9(4):413-425.

20. Young AH, McElroy SL, Bauer M, et al. A double-blind, placebocontrolled study of quetiapine and lithium monotherapy in adults in the acute phase of bipolar depression (EMBOLDEN I). J Clin Psychiatry. 2010;71(2):150-162.

21. Paulsson B, Olausson B, McElroy SL, Chang W, Young AH. Quetiapine monotherapy up to 52 weeks in patients with bipolar depression: continuation phase data from the EMBOLDEN I and II studies. Poster presented at the World Psychiatric Association International Congress, Florence, Italy, April 1-4, 2009. 
22. Suppes T, Vieta E, Liu S, Brecher M, Paulsson B. Maintenance treatment for patients with bipolar I disorder: results from a North American study of quetiapine in combination with lithium or divalproex (trial 127). Am J Psychiatry. 2009;166:479-488.

23. Vieta E, Suppes T, Eggens I, Persson I, Paulsson B, Brecher M. Efficacy and safety of quetiapine in combination with lithium or divalproex for maintenance of patients with bipolar I disorder (international trial 126). $J$ Affect Disord. 2008;109(3):251-263.

24. Endicott J, Rajagopalan K, Minkwitz M, Macfadden W. A randomized, double-blind, placebo-controlled study of quetiapine in the treatment of bipolar I and II depression: improvements in quality of life. Int Clin Psychopharmacol. 2007;22(1):29-37.

25. Endicott J, Paulsson B, Gustafsson U, Schioler H, Hassan M. Quetiapine monotherapy in the treatment of depressive episodes of bipolar I and II disorder: improvements in quality of life and quality of sleep. $J$ Affect Disord. 2008;111(2-3):306-319.

26. Hirschfeld RM, Weisler RH, Raines SR, Macfadden W. Quetiapine in the treatment of anxiety in patients with bipolar I or II depression: a secondary analysis from a randomized, double-blind, placebocontrolled study. J Clin Psychiatry. 2006;67(3):355-362.

27. AstraZeneca. Seroquel XR (quetiapine fumarate) extended-release tablets/US prescribing information [updated Jul 2011]. Available from: http://www1.astrazeneca-us.com/pi/seroquelxr.pdf. Accessed November 14, 2011

28. Saini SD, Schoenfeld P, Kaulback K, Dubinsky MC. Effect of medication dosing frequency on adherence in chronic diseases. Am J Manag Care. 2009;15(6):e22-e33.

29. Ascher-Svanum H, Faries DE, Zhu B, Ernst FR, Swartz MS, Swanson JW. Medication adherence and long-term functional outcomes in the treatment of schizophrenia in usual care. J Clin Psychiatry. 2006;67(3):453-460.

30. Leucht S, Heres S. Epidemiology, clinical consequences, and psychosocial treatment of nonadherence in schizophrenia. J Clin Psychiatry. 2006;67(Suppl 5):3-8.

31. AstraZeneca. Seroquel XR and Seroquel Approved in Europe for Prevention of Recurrence of Bipolar Disorder [updated 2009]. Available from: http://www.astrazeneca.com/media/latest-press-releases/2009/ Seroquel_Bipolar_Maint_EU?itemId=7082393. Accessed January 21, 2010.

32. AstraZeneca. US FDA Approves Seroquel XR For Add-On Treatment Of Major Depressive Disorder [updated 2009]. Available from AstraZeneca. Accessed January 21, 2010.

33. AstraZeneca. Seroquel XR Recommended For Approval In EU as an Add-On Treatment Of Major Depressive Disorder [updated 2010]. Available from: http://www.astrazeneca.com/media/latest-pressreleases/seroquelXR-MDD?itemId=9260911. Accessed April 23, 2010 .

34. DeVane CL, Nemeroff CB. Clinical pharmacokinetics of quetiapine: an atypical antipsychotic. Clin Pharmacokinet. 2001;40(7): 509-522.

35. Nemeroff CB, Kinkead B, Goldstein J. Quetiapine: preclinical studies, pharmacokinetics, drug interactions, and dosing. J Clin Psychiatry. 2002;63(Suppl 13):5-11.

36. Figueroa C, Brecher M, Hamer-Maansson JE, Winter H. Pharmacokinetic profiles of extended release quetiapine fumarate compared with quetiapine immediate release. Prog Neuropsychopharmacol Biol Psychiatry. 2009;33(2):199-204.

37. Juckel G, Winter HR, Ståhle L, Miller F, Strid S. The pharmacokinetics of extended release quetiapine fumarate are not affected by a light meal. Schizophr Res. 2008;98(Suppl):163.

38. AstraZeneca. Seroquel (quetiapine fumarate) - US prescribing information [updated 2008]. Available from: http://www1.astrazeneca-us.com/ pi/seroquel.pdf. Accessed May 2, 2012.

39. Nyberg S, Widzowski D. Translational pharmacology of quetiapine and norquetiapine: preclinical findings support multifunctional psychotropic properties. Eur Psychiatry. 2010;25(Suppl 1):1446, PW01-27(Abstract).
40. Goldstein JM, Christoph G, Grimm S, Liu J, Widzowski D, Brecher M. Quetiapine's antidepressant properties: direct and indirect pharmacologic actions on norepinephrine and serotonin receptors. Eur Neuropsychopharmacol. 2007;17(Suppl 4):S401.

41. Jensen NH, Rodriguiz RM, Caron MG, Wetsel WC, Rothman RB, Roth BL. N-desalkylquetiapine, a potent norepinephrine reuptake inhibitor and partial 5-HT (1A) agonist, as a putative mediator of quetiapine's antidepressant activity. Neuropsychopharmacology. 2008;33(10):2303-2312.

42. Nyberg S, Takano A, Grimm S, et al. PET-measured D2, 5-HT2, and norepinephrine transporter (NET) occupancy by quetiapine and N-desalkylquetiapine in non-human primates. Eur Neuropsychopharmacol. 2007;17(Suppl 4):S254-S255.

43. Horacek J, Bubenikova-Valesova V, Kopecek M, et al. Mechanism of action of atypical antipsychotic drugs and the neurobiology of schizophrenia. CNS Drugs. 2006;20(5):389-409.

44. Kapur S, Remington G, Jones C, et al. High levels of dopamine D2 receptor occupancy with low-dose haloperidol treatment: a PET study. Am J Psychiatry. 1996;153(7):948-950.

45. Nordstrom AL, Farde L, Wiesel FA, et al. Central D2-dopamine receptor occupancy in relation to antipsychotic drug effects: a double-blind PET study of schizophrenic patients. Biol Psychiatry. 1993;33(4):227-235.

46. Pani L, Pira L, Marchese G. Antipsychotic efficacy: relationship to optimal D2-receptor occupancy. Eur Psychiatry. 2007;22(5):267-275.

47. Seeman P. Atypical antipsychotics: mechanism of action. Can J Psychiatry. 2002;47(1):27-38.

48. Roth BL, Sheffler D, Potkin SG. Atypical antipsychotic drug actions: unitary or multiple mechanisms for "atypicality"? Clin Neurosci Res. 2003;3:108-117.

49. Kapur S, Seeman P. Antipsychotic agents differ in how fast they come off the dopamine $\mathrm{D}_{2}$ receptors. Implications for atypical antipsychotic action. J Psychiatry Neurosci. 2000;25(2):161-166.

50. Nord M, Nyberg S, Brogren J, Jucaite A, Halldin C, Farde L. Comparison of $\mathrm{D}_{2}$ dopamine receptor occupancy after oral administration of quetiapine fumarate immediate-release and extended-release formulations in healthy subjects. Int $J$ Neuropsychopharmacol. 2011;14(10):1357-1366.

51. Mamo DC, Uchida H, Vitcu I, et al. Quetiapine extended-release versus immediate-release formulation: a positron emission tomography study. J Clin Psychiatry. 2008;69(1):81-86.

52. Peuskens J, Trivedi JK, Malyarov S, et al. Prevention of schizophrenia relapse with extended release quetiapine fumarate dosed once daily: a randomized placebo-controlled trial in clinically stable patients. Psychiatry (Edgemont). 2007;4(11):34-50.

53. Ganesan S, Agambaram V, Randeree F, et al. Switching from other antipsychotics to once-daily extended release quetiapine fumarate in patients with schizophrenia. Curr Med Res Opin. 2008;24(1): 21-32.

54. Moller HJ, Johnson S, Mateva T, et al. Evaluation of the feasibility of switching from immediate release quetiapine to extended release quetiapine fumarate in stable outpatients with schizophrenia. Int Clin Psychopharmacol. 2008;23(2):95-105.

55. Lindenmayer JP, Brown D, Liu S, Brecher M, Meulien D. The efficacy and tolerability of once-daily extended release quetiapine fumarate in hospitalized patients with acute schizophrenia: a 6-week randomized, double-blind, placebo-controlled study. Psychopharmacol Bull. 2008; 41(3):11-35

56. Suppes T, Datto C, Minkwitz M, Nordenhem A, Walker C, Darko D. Effectiveness of the extended release formulation of quetiapine as monotherapy for the treatment of acute bipolar depression. $J$ Affect Disord. 2010;121(1-2):106-115.

57. Cutler AJ, Tran-Johnson T, Kalali A, Astrom M, Brecher M, Meulien D. A failed 6-week, randomized, double-blind, placebo-controlled study of once-daily extended release quetiapine fumarate in patients with acute schizophrenia: lessons learned. Psychopharmacol Bull. 2010;43(4): 37-69 
58. Cutler AJ, Datto C, Nordenhem A, Minkwitz M, Acevedo L, Darko D. Extended-release quetiapine as monotherapy for the treatment of adults with acute mania: a randomized, double-blind, 3-week trial. Clin Ther. 2011;33(11):1643-1658.

59. Kahn RS, Schulz SC, Palazov VD, et al. Efficacy and tolerability of once-daily extended release quetiapine fumarate in acute schizophrenia: a randomized, double-blind, placebo-controlled study. J Clin Psychiatry. 2007;68(6):832-842.

60. Kahn R, Kalali A, Gustafsson U, Nyberg S. Efficacy and tolerability of quetiapine XR 400/600/800 mg/day in acute schizophrenia: a post hoc analysis of data from two pooled randomised studies. Poster presented at the 19th EPA European Congress of Psychiatry; Vienna, Austria, March 12-15, 2011.

61. Kasper S, Montagnani G, Trespi G. Extended release quetiapine fumarate (quetiapine XR) versus risperidone in the treatment of depressive symptoms in schizophrenic or schizoaffective patients. Poster presented at the 19th EPA European Congress of Psychiatry; Vienna, Austria, March 12-15, 2011.

62. Peuskens J, Trivedi JK, Brecher M, Miller F. Long-term symptomatic remission of schizophrenia with once-daily extended release quetiapine fumarate: post-hoc analysis of data from a randomized withdrawal, placebo-controlled study. Int Clin Psychopharmacol. 2010;25: 183-187.

63. Meulien D, Huizar K, Brecher M. Safety and tolerability of once-daily extended release quetiapine fumarate in acute schizophrenia: pooled data from randomised, double-blind, placebo-controlled studies. Hum Psychopharmacol. 2010;25(2):103-115.

64. Cutler A, Earley W, Datto C, et al. Effectiveness of the extended release formulation of quetiapine as monotherapy for the treatment of acute bipolar mania. Int J Neuropsychopharmacol. 2008:11(Suppl 1): 184-185.

65. Datto C, Berggren L, Patel JB, Eriksson H. Self-reported sedation profile of immediate-release quetiapine fumarate compared with extendedrelease quetiapine fumarate during dose initiation: a randomized, double-blind, crossover study in healthy adult subjects. Clin Ther. 2009;31(3):492-502.
66. Bauer M, Pretorius HW, Constant EL, Earley WR, Szamosi J, Brecher M. Extended-release quetiapine as adjunct to an antidepressant in patients with major depressive disorder: results of a randomized, placebo-controlled, double-blind study. J Clin Psychiatry. 2009;70(4): 540-549.

67. Bortnick B, El-Khalili N, Banov M, et al. Efficacy and tolerability of extended release quetiapine fumarate (quetiapine XR) monotherapy in major depressive disorder: a placebo-controlled, randomized study. J Affect Disord. 2011;128(1-2):83-94.

68. Cutler AJ, Montgomery SA, Feifel D, Lazarus A, Åström M, Brecher M. Extended release quetiapine fumarate monotherapy in major depressive disorder: a placebo- and duloxetine-controlled study. J Clin Psychiatry. 2009; 70(4):526-539.

69. El-Khalili N, Joyce M, Atkinson S, et al. Extended-release quetiapine fumarate (quetiapine XR) as adjunctive therapy in major depressive disorder (MDD) in patients with an inadequate response to ongoing antidepressant treatment: a multicentre, randomized, double-blind, placebo-controlled study. Int J Neuropsychopharmacol. 2010;13(7): 917-932.

70. Liebowitz M, Lam RW, Lepola U, Datto C, Sweitzer D, Eriksson H. Efficacy and tolerability of extended release quetiapine fumarate monotherapy as maintenance treatment of major depressive disorder: a randomized, placebo-controlled trial. Depress Anxiety. 2010;27(10):964-976.

71. Weisler R, Joyce M, McGill L, Lazarus A, Szamosi J, Eriksson H. Extended release quetiapine fumarate monotherapy for major depressive disorder: results of a double-blind, randomized, placebo-controlled study. CNS Spectr. 2009;14(6):299-313.

72. Locklear J, Wahlqvist P, Gustafsson U, Udd M, Fajutrao L, Eriksson H. The impact of once-daily extended release quetiapine fumarate (quetiapine XR) on length and costs of hospitalisation of patients with schizophrenia or bipolar disorder. Value Health. 2011;14(7):A299.

73. Gao K, Ganocy SJ, Gajwani P, Muzina DJ, Kemp DE, Calabrese JR. A review of sensitivity and tolerability of antipsychotics in patients with bipolar disorder or schizophrenia: focus on somnolence. J Clin Psychiatry. 2008;69(2):302-309.
Neuropsychiatric Disease and Treatment

\section{Publish your work in this journal}

Neuropsychiatric Disease and Treatment is an international, peerreviewed journal of clinical therapeutics and pharmacology focusing on concise rapid reporting of clinical or pre-clinical studies on a range of neuropsychiatric and neurological disorders. This journal is indexed on PubMed Central, the 'PsycINFO' database and CAS.

\section{Dovepress}

The manuscript management system is completely online and includes a very quick and fair peer-review system, which is all easy to use. Visit http://www.dovepress.com/testimonials.php to read real quotes from published authors. 